\title{
A traffic congestion problem and solutions: the road between Sawz Square and Shahidan Square in Koya city as a case study
}

\author{
P. J. Muhammad Ali \& R. H. Faraj \\ Koya University, Iraq
}

\begin{abstract}
One of the big problems facing city municipalities is the traffic congestion. It makes life in cities uncomfortable for people. Every year governments spend huge budgets to solve this problem. Koya is suffering from this problem especially at rush traffic hours. In this paper, the traffic congestion problem is studied for the road connecting Sawz Square and Shahidan Square in Koya city. The congestion is measured by determining the level of service of the street (LOS) through calculating the traffic flow rate of the street and free flow rate; the LOS level was D. For determining peak hour traffic volume the calculation is made through the manual counting of vehicles and multiplying by passenger car equivalent (PCE) where the speed is reduced to $(10 \mathrm{~km} / \mathrm{hr})$. In addition, the topography, elevations and alignments of the road are studied. This paper determined the real causes of the traffic congestion in this specific street in Koya city and proposed solutions for solving the problem.
\end{abstract}

Keywords: traffic congestion, peak hour traffic, traffic jam, urbanization.

\section{Introduction}

One of the most challenging and complicated issues in city life is the traffic problem. In Iraq, development in the number of roads and transportation infrastructure is not enough to fulfil the rapid increase in the number of vehicles. Opening boarders for importing vehicles without any kind of planning makes Iraq especially Kurdistan region a big garage for vehicles. The absence of active public transportation is also one of the causes of congestion problem. The reasons causing traffic congestion is not generic, it may differ from a road to another, there may be common causes but still roads have their specific reasons 
for congestion. The increase in population and high income of individuals in any country has its effects on the existing transportation systems. This study will concentrate on the causes of the traffic congestion on a specific road in Koya city as well as the solutions to avoid traffic congestion.

Koya is one of the cities of the Kurdistan region. The main road connecting two major cities of Kurdistan, Sulaimanya and Erbil is going through this city and exactly through this street. Figure 1 is a satellite image showing the strategic location of the city. The increase in the individuals' income pushed people to buy passenger cars. The development in road infrastructure in the city is not adequate to accompany the high number of vehicles in the city. Since the end of 80 s, there is no noticeable infrastructure development in the city especially in the downtown roads. The city grew randomly without planning and new quarters were built with a little planning while city development needs a deep plan.

The congestion problem is a common problem among developed and underdeveloped countries, so, it's a global problem [1]. The traffic congestion leads to other kinds of problems especially in big cities, according to a study conducted in cities of Sweden the traffic jam caused a noise pollution too [2]. Other studies showed that development in any county in the world is not perfect if traffic congestion results big economic costs [3]. Traffic congestion easily causes traffic jams; a traffic jam occurs when vehicles are fully stopped for a long period of time [4].

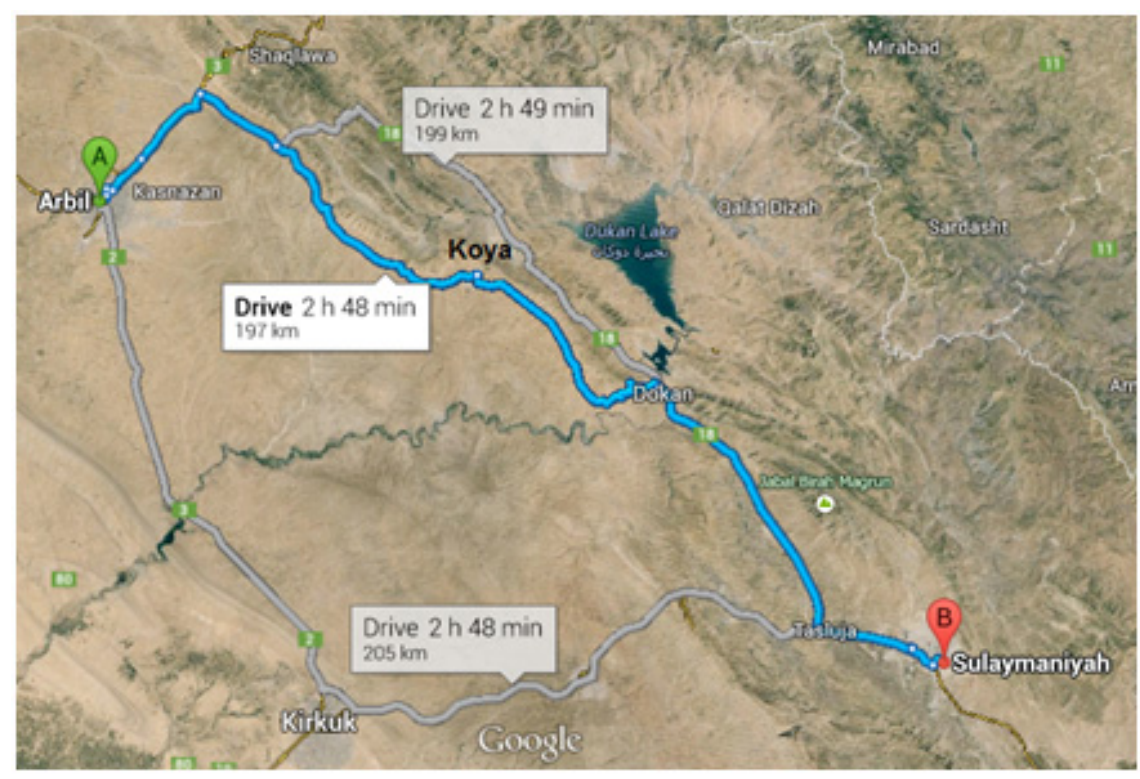

Figure 1: $\quad$ Koya city located south east of Erbil. 
The objective of this study is to find the real causes behind the traffic congestion on the street connecting two major squares - Sawz Square and Shahidan Square - in Koya city and to conclude possible solutions for the problem.

\section{Area under consideration}

The study area is a road (300 m) length connects two major squares in Koya city - Sawz Square and Shahidan Square (fig. 2 shows a satellite image of the street). The average width of the road is $25 \mathrm{~m}$. According to the regulations of the traffic management system the way is bidirectional, two lanes in each direction. This street is one of the most important roads in the city which located on the main road connecting two big cities Sulaimanya and Erbil in the Kurdistan region. Also, it is the main road to the Koya University and other important governmental offices. There are a number of shops in the south side of the road while most of the buildings on the north side are governmental and public. The price of one square meter of a land surrounding the area of the study is relatively higher than other places of the city. Both squares are signalized and controlled by traffic lights, but continuous interruption of the electrical power supplying traffic lights is another cause of the congestion.

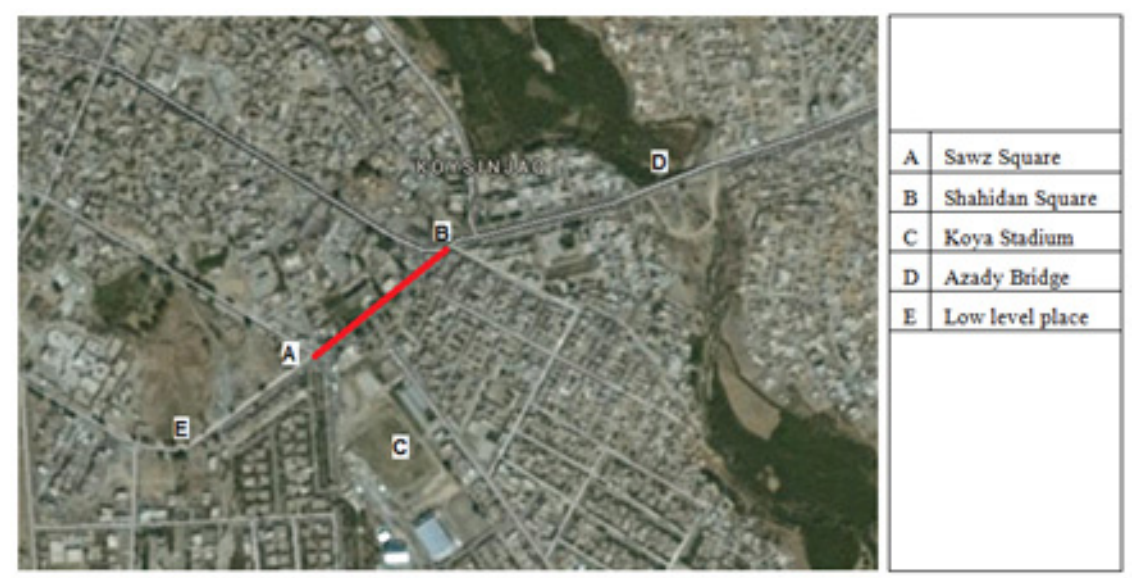

Figure 2: $\quad$ The area under consideration.

\section{Methodology}

Two stations where fixed for determining flow rate by manual counting of vehicles passing these stations in an hour. The first station was located $70 \mathrm{~m}$ from point $A$, the second one is positioned about $70 \mathrm{~m}$ from point $\mathrm{B}$. Traffic flow rate in the B-A direction was the same in the two stations while there was a difference in the flow rate for the A-B direction, this difference caused by the Jalizada sub-road which comes from south and joins the road under study (as in fig. 3). 


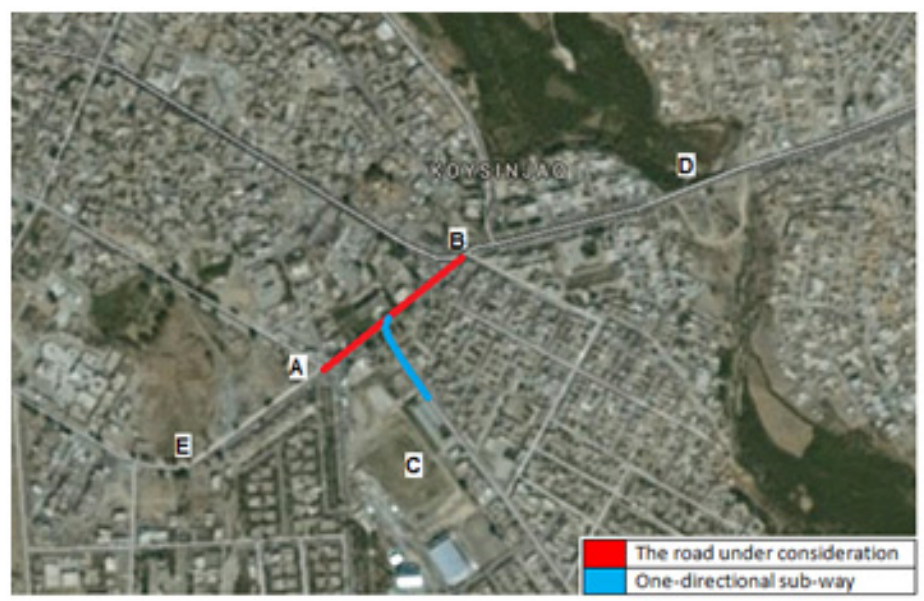

Figure 3: Jalizada sub-road flows in the street under consideration.

\subsection{Travel speed}

For determining the average speed of the vehicles the License Plate method is used, the observers were positioned in the two stations. In this method the observer is required to take the last four digits of some of the vehicles passing the road at the first station, as well as the time of passing this station is also recorded. The time of arrival to the second station is also recorded with the last four digits of the vehicle. It's not possible to do this process for all vehicles, only some vehicles can be recorded in both stations. The difference between two recorded times is the travel time of this vehicle. The average of travel time can be calculated as a mean of observed travel time of all vehicles, eqn. (1) can be used for determining the average travel speed.

$$
S=\frac{n * L * 3.6}{\sum_{1}^{n} t_{i}}
$$

where: $\mathrm{S}$ is the average travel speed in $\mathrm{kph}, \mathrm{n}$ is number of matched plates, $\mathrm{L}$ is the length of the test section (m), in this case $\mathrm{L}=160 \mathrm{~m}$, $\mathrm{t}$ is the recorded time in seconds.

\subsection{Travel volume}

The rate of flow is measured throughout one week to take in consideration all different days of the week including the weekend from 06:00 to 23:00. Late night hours were neglected because traffic flow is reduced too much. The counting intervals were 15 minutes. Fig. 4 shows a sample of the sheets used in the counting process. 
Date:

\begin{tabular}{|c|c|c|c|c|c|}
\hline Time & $\begin{array}{c}A-\mathrm{B} \\
\mathrm{V} / 15 \mathrm{~min},\end{array}$ & $\begin{array}{c}\mathrm{B}-\mathrm{A} \\
\mathrm{V} / 15 \mathrm{~min} .\end{array}$ & Time & $\begin{array}{c}\mathrm{A}-\mathrm{B} \\
\mathrm{V} / 15 \mathrm{~min} .\end{array}$ & $\begin{array}{c}\mathrm{B}-\mathrm{A} \\
\mathrm{V} / 15 \mathrm{~min},\end{array}$ \\
\hline $6: 00-6: 15$ & & & $15: 00-15: 15$ & & \\
\hline $6: 15-6: 30$ & & & $15: 15-15: 30$ & & \\
\hline $6: 30-6: 45$ & & & $15: 30-15: 45$ & & \\
\hline $6: 45-7 ; 00$ & & & $15: 45-16: 00$ & & \\
\hline $7: 00-7: 15$ & & & $16: 00-16: 15$ & & \\
\hline $7: 15-7: 30$ & & & $16: 15-16: 30$ & & \\
\hline $7: 30-7: 45$ & & & $16: 30-16: 45$ & & \\
\hline $7: 45-8: 00$ & & & $16: 45-17: 00$ & & \\
\hline $8: 00-8: 15$ & & & $17: 00-17: 15$ & & \\
\hline $8: 15-8: 30$ & & & $17: 15-17: 30$ & & \\
\hline $8: 30-8: 45$ & & & $17: 30-17: 45$ & & \\
\hline $8: 45-0: 00$ & & & $17: 45-18: 00$ & & \\
\hline
\end{tabular}

Figure 4: $\quad$ Sample of the sheets used in the process of determining traffic volume.

The flow diagram in the direction A-B is shown in fig. 5, the flow diagram in the direction B-A is shown in fig. 6. Because of the differences in the rate of flow between two stations in the A-B direction the average of the two stations is calculated and used in the flow diagram of fig. 5 .

Every day two peak hours occur one at 8:00 and the second one at 18:00, also there is another little peak occurs at 12:00, but it's not high to be considered as a rush hour. The noticeable thing here is that, peak hours occur at the same time in both directions. The first rush hour is occurring at the beginning of the working day which is normal in all countries though out the world. The second rush hour occurs on evenings when people going back to their homes. Another cause of the evening rush hour is a parallel parking, because of clinics working time.

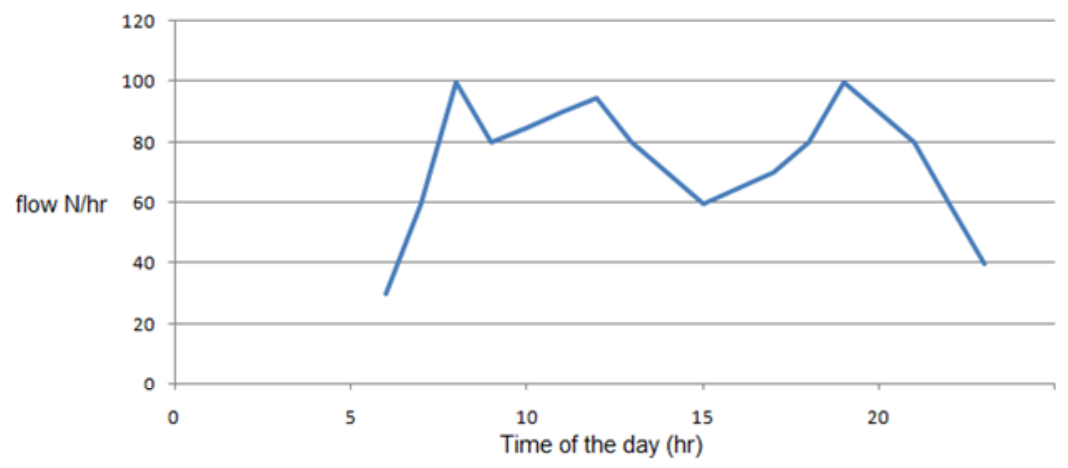

Figure 5: $\quad$ Traffic flow rate in the direction A-B. 


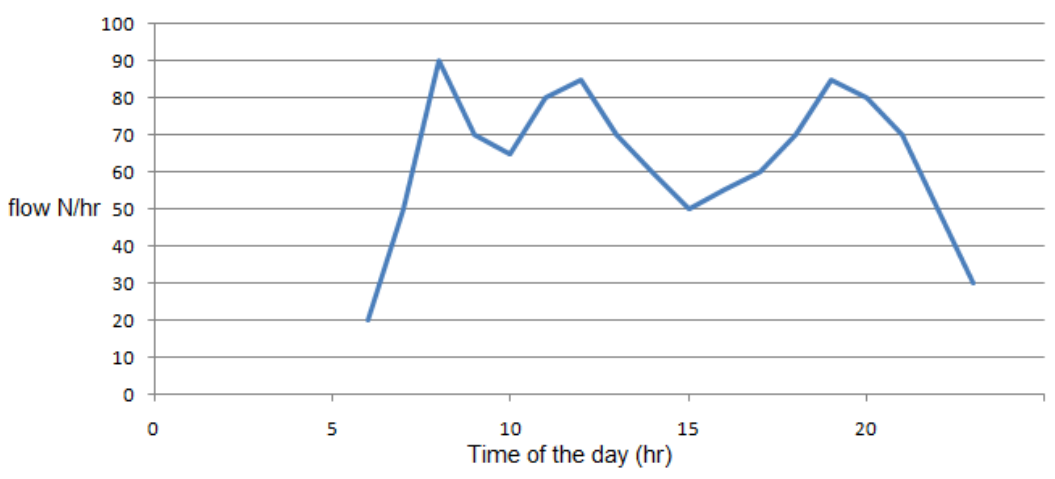

Figure 6: $\quad$ Traffic flow rate in the direction B-A.

\subsection{Passenger car equivalent}

Passenger Car Equivalent (PCE) is a metric used to assess traffic-flow rate on highways. A Passenger Car Equivalent is the impact that a mode of transport has on traffic variables such as speed or volume of traffic if compared to a single car. The equivalent values for each kind of vehicles are shown in table 1.

Table 1: $\quad$ Passenger car equivalent.

\begin{tabular}{|l|c|}
\hline Passenger car (including private cars, taxi, and pickups) & 1 \\
\hline Bus, tractor, truck & 3.5 \\
\hline Motorcycle & 0.5 \\
\hline Bicycle & 0.2 \\
\hline Horse-drawn vehicles & 4 \\
\hline
\end{tabular}

In this study, most of the vehicles were private cars, taxies, pickups, buses, and tractors. Some Motorcycles were also recorded. Bicycles were not recorded because of their little effect and horse-drawn vehicles did not exist. Observers directly multiplied the number of vehicles by their equivalent values to get the PCE/ 15 mints, and then PCE/ h.

\subsection{Free flow speed}

Free flow Speed (FFS) is the average speed of a vehicle in a specific road, it must be observed during very low traffic volume conditions or late night hours while drivers are not constrained by other vehicles or by traffic signals, FFS is measured using test car.

In this study, the FFS is obtained by marking runs with a test car during periods of late night hours. The FFS can be determined as the average of several speed reading of the car in different five nights according to eqn. (2).

$$
F F S=\sum_{i=1}^{n} s_{i} / n
$$


where: FFS is the free flow speed (Kph), $\mathrm{n}$ is number of samples in this case is 5 , and $\mathrm{s}$ is the vehicle speed reading in each time (Kph). In this study, the FFS was $45 \mathrm{Kph}$.

\section{Level of service}

Level of service (LOS) is a measure used to determine the effectiveness of elements of transportation infrastructure. LOS is most commonly used to analyse highways by categorizing traffic flow with corresponding safe driving conditions. According to Highway Capacity Manual (HCM) and AASHTO Geometric Design of Highways and Streets, the levels of service for any highway or street is ranked using letters A through $\mathrm{F}$, with A being the best and $\mathrm{F}$ being the worst.

The LOS can be determined based on FFS and average travel speed [5], table 2 shows the level of service for roads classified according to the FFS and average travel speeds.

Table 2: $\quad$ Level of service (LOS) according to free flow traffic.

\begin{tabular}{|c|c|c|c|c|}
\hline Street class & I & II & III & IV \\
\hline FFS & 89 to $72 \mathrm{kph}$ & 72 to $56 \mathrm{kph}$ & 56 to $48 \mathrm{kph}$ & 56 to $40 \mathrm{kph}$ \\
\hline Typical FFS & $80 \mathrm{kph}$ & $64 \mathrm{kph}$ & $56 \mathrm{kph}$ & $48 \mathrm{kph}$ \\
\hline LOS & \multicolumn{4}{|c|}{ Average travel speed $(\mathrm{kph})$} \\
\hline A & $>68$ & $>56$ & $>48$ & $>40$ \\
\hline B & $>55-68$ & $>45-56$ & $>39-48$ & $>31-40$ \\
\hline C & $>43-55$ & $>35-45$ & $>29-39$ & $>21-31$ \\
\hline D & $>34-43$ & $>27-35$ & $>23-29$ & $>14-21$ \\
\hline E & $>26-34$ & $>21-27$ & $>16-23$ & $>11-14$ \\
\hline F & $\leq 26$ & $\leq 21$ & $\leq 16$ & $\leq 11$ \\
\hline
\end{tabular}

The street is class IV because the FFS of the street is $45 \mathrm{kph}$, the average vehicle speed is $15 \mathrm{kph}$ therefore the LOS of the street is D. Level of service D is not a good level, this paper suggests solutions to increase this level to A or B level.

\section{Reasons for traffic congestion}

This research tries to focus on the real causes of the congestion in peak hours. Traffic congestion is a local problem not generic the reasons differ from one case to another and is directly related to the road under study. The causes may vary from place to another even in the same city or the same country, therefore, not all the reasons and solutions can be generalized. In fact, all causes of the traffic congestion mentioned below affect each other. Causes are: 
- Parallel parking

Parallel parking is parking the vehicle beside the road in the direction of flow. In the study area the parking is allowed in the A-B direction, but not allowed in the B-A direction. It's noticeable that parallel parking effectively affects the flow of the traffic, especially at rush hours where vehicle parks illegally as a second parallel row and leads to a decrease in the number of lanes to only one lane.

- Number of vehicles

Generally, the number of cars in the Kurdistan region is relatively high if compared with the capacity of roads; this number is in a continuous increase while there is not adequate level of development in the number of road and traffic infrastructure. In Koya, number of vehicles is in a fast increase and roads are in a bad quality.

- Width of the street

Streets width is not constant, it varies along the road. The width of the street in the narrowest section is $23 \mathrm{~m}$, and in the widest section is $27 \mathrm{~m}$.

- School, clinics, offices

There are a number of clinics, offices, a school, governmental and public buildings and a bank on the street, they have an effect on the traffic flow in the peak hours.

- City planning

New quarters in the city was built without planning. New quarters are just appended to old quarters without constructing roads serves these new areas. New quarters depend totally on the roads of older quarters. Because of this reason there is a heavy traffic on this road. It can be said that Koya is a random built city, there is no serious city planning.

\section{Proposed solutions}

Traffic congestion can be reduced by either reducing traffic flow or increasing road capacity [4]. Because reasons of this kind of problem are local not generic, therefore, solutions are also specific to this case only and it can't be applied to other cases in different cities, below are the solutions proposed by this paper:

- Road widening

The first solution clicks in the mind is the possibility of widening the road. The north side of the street is \%90 governmental and public estates that can be widened easily with a relatively little budget.

- Constructing highway

The main traffic between two big cities Erbil and Sulaimanya is going through this road. Constructing a highway outside city centre will effectively reduce the traffic load on the study area.

- Building tunnel

The street ends with two low elevation roads as shown in the fig. 7 , the difference in elevation between point A which is Sawz Square and point E is $7.5 \mathrm{~m}$, while the difference between point B which is Shahidan Square and point D which is Azady Bridge is about $9.0 \mathrm{~m}$. This difference in elevation tells us that the street was built on a hill which makes it perfect topology for building 


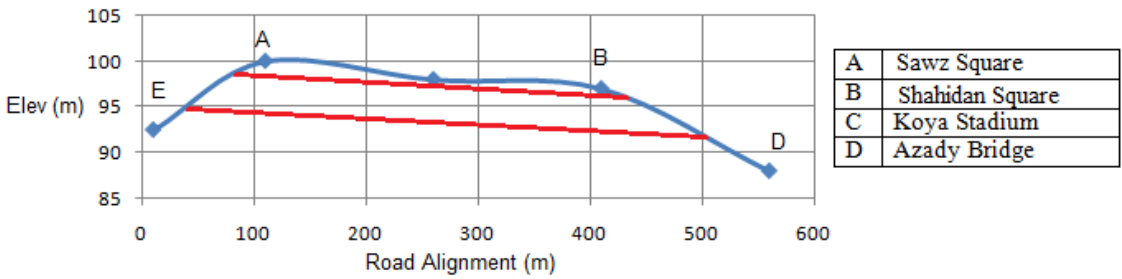

Figure 7: $\quad$ The alignment and elevations of the street under consideration.

a tunnel under the road. Building a tunnel with a length about 330m provides the city a kind of urban style.

- Controlling number vehicles

Controlling number of the cars imported to the region has a positive effect on controlling congestion problems in all cities in the region.

- Combined solution

The first three proposed solutions above can be combined with each other to give better results.

\section{Conclusions}

This paper concluded that there is a traffic congestion problem at the street between Sawz intersection and Shahidan Square in Koya city with high expectation to increase in future. The level of service of the street is D. Widening the road is the best solution for deceasing the congestion, because it raises the LOS to level B with a low cost if compared with other suggestions. Building a tunnel gives the city a kind of urbanized look, but with higher costs.

\section{References}

[1] Najneen, F., Hoque, K.S., Mahmood, S.M.S., Rahman, S. \& Sharmin, M. Traffic congestion due to unplanned activities. Bangladesh research publications Journal, 4(2), pp. 185-197, 2010.

[2] Bjork, J., Ardo, J., Stroh, E., Lovkvist, E., Ostergren, P. \& Albin, M., Road traffic noise in southern Sweden and its relation to annoyance, disturbance of daily activities and health. Scandinavian Journal of Work, Environment, and Health, 32(5), pp. 392-401, 2006.

[3] Chien, M.K. \& Shih, L.H., An empirical study of the implementation of green supply chain management practices in the electrical and electronic industry and their relation to organizational performances. International Journal of Environmental Science and Technology, 4(3), pp. 383-394, 2007.

[4] Remi, A.J., Adegoke, A.A.I., Oyerinde, A.J, A Study of the Causes, Effects and Ameliorative Measures of Road Traffic Congestion in Lagos Metropolis. European journal of Social Sciences, 11(1), pp. 119-128, 2009.

[5] Transportation research board, Highway capacity manual 2000, National Academy of Sciences, p.10-1, 2000. 